\title{
Management of acute type $B$ aortic dissection
}

\author{
G. Chad Hughes, MD, ${ }^{a}$ Nicholas D. Andersen, MD, ${ }^{a}$ and Richard L. McCann, MD $^{\mathrm{b}}$
}

Acute type B aortic dissection (identified within 2 weeks of symptom onset), as described using the Stanford classification, involves the aorta distal to the left subclavian artery and accounts for $25 \%-40 \%$ of all aortic dissections. The traditional treatment paradigm of medical management for uncomplicated acute type B dissection and open surgical intervention for early or late complications of type B dissection is currently undergoing a period of evolution as a result of the influence of minimally invasive thoracic endovascular aortic repair options. Thoracic endovascular repair has replaced open surgical repair as the preferred treatment for complicated acute type B dissection, and may also prove beneficial for prophylactic repair of uncomplicated acute type B dissection for high-risk patients. This review discusses the management of acute type B aortic dissection and long-term treatment considerations. (J Thorac Cardiovasc Surg 2013;145:S202-7)

Acute type B dissections may be classified as uncomplicated or complicated, with complicated disease generally referring to the presence of rupture or impending rupture, malperfusion, and/or refractory pain or hypertension. ${ }^{1}$ Complicated dissections, which represent $15 \%$ to $20 \%$ of cases, require surgical or interventional therapy, and Thoracic endovascular aortic repair (TEVAR) has generally replaced open surgery or fenestration as the treatment of choice for this clinical problem.

For patients with dynamic malperfusion caused by branch vessel occlusion of the true lumen by the pressurized false lumen (Figure $1^{2,3}$ ), endovascular treatment aims to restore antegrade flow within the true lumen and reduce false lumen flow by stent graft coverage of the primary tear. Additional distal bare-metal stenting of the visceral segment and/or iliacs may be required to reexpand the distal true lumen, and femoral-femoral bypass may be required for long-segment unilateral iliac occlusion (Figure 2). For patients with static malperfusion caused by propagation of the dissection into branch vessel ostia with distal vessel occlusion (Figure 1), coverage of the primary tear and restoration of true lumen flow alone generally does not relieve the malperfusion syndrome, and thus endovascular treatment also requires branch vessel stenting (Figure 3), and surgical bypass may ultimately be required

From the Division of Cardiovascular and Thoracic Surgery a and the Division of Vascular Surgery, ${ }^{\mathrm{b}}$ Duke University Medical Center, Durham, NC.

Disclosures: Dr Hughes is a consultant for Medtronic, St. Jude Medical, W.L. Gore and Associates, and Vascutek; a member of the speaker's bureau for Medtronic, W.L. Gore and Associates, and Vascutek; and received unrestricted research grants from W.L. Gore and Associates and Vascutek. Drs Andersen and McCann have nothing to disclose with regard to commercial support.

Read at The American Association for Thoracic Surgery Aortic Symposium, New York, New York, April 26-27, 2012.

Received for publication April 30, 2012; revisions received Oct 10, 2012; accepted for publication Nov 28, 2012; available ahead of print Dec 26, 2012.

Address for reprints: G. Chad Hughes, MD, Duke Heart Center, Division of Thoracic and Cardiovascular Surgery, Duke University Medical Center, Box 3051, Durham, NC 27710 (E-mail: gchad.hughes@ duke.edu).

$0022-5223 / \$ 36.00$

Copyright (c) 2013 by The American Association for Thoracic Surgery

http://dx.doi.org/10.1016/j.jtcvs.2012.11.078 if endovascular attempts are unsuccessful. ${ }^{2}$ Regardless of the management approach, this form of malperfusion is associated with significant mortality, especially if the static malperfusion process involves the visceral vessels. ${ }^{4}$ For patients with contained or frank rupture (Figure 4), endovascular repair is more complex and requires sealing off the primary tear as well as the site of the leak, and frequently necessitates paving the entire thoracic aorta when the site of the leak is unclear.

Intravascular ultrasound and transesophageal echocardiography are superior to angiography for identifying primary and distal reentry tears, documenting guidewire position in the true lumen, assessing seal zones, and detecting endoleaks, ${ }^{5}$ and are used for all TEVAR dissection cases at our institution (Figure 5). We also consider intravascular ultrasound and transesophageal echocardiography assessment of the ascending aorta to be mandatory at the conclusion of each TEVAR case to assess for retrograde ascending aortic dissection, a catastrophic complication of TEVAR that occurs more frequently when treating dissection (Figure 5). ${ }^{6,7}$ Thoracic endovascular aortic repair is generally avoided in patients with connective tissue disease because of a high rate of treatment failure; however, endovascular therapy may provide a successful bridge to open treatment in select patients with connective tissue disease with complicated acute type B dissection, provided careful follow-up at an experienced aortic center is ensured. ${ }^{8,9}$

Observational data comparing endovascular therapy with open repair of acute complicated type B dissection favor overwhelmingly the endovascular approach. For example, the International Registry of Acute Aortic Dissection (IRAD) reported an in-hospital death rate of $33 \%$ for patients with acute complicated type B dissection treated by open surgery, compared with $11 \%$ for patients treated by endovascular therapy. ${ }^{10} \mathrm{~A}$ metaanalysis of 29 studies reporting outcomes after endovascular repair of acute complicated type B dissection further reported an in-hospital mortality rate of $9 \% .{ }^{11}$ The use of TEVAR for complicated dissection remains 
Abbreviations and Acronyms

IRAD = International Registry of Acute Aortic Dissection

TEVAR $=$ thoracic endovascular aortic repair investigational in the United States, although clinical trials to gain U.S. Food and Drug Administration approval are complete or nearly complete. Nonetheless, consensus statements from the Society of Thoracic Surgeons and the American Heart Association have already supported the use of TEVAR for acute complicated type B dissection.,12

\section{UNCOMPLICATED ACUTE TYPE B DISSECTION}

Medical management with anti-impulse therapy has remained the preferred treatment option for uncomplicated acute type B dissection, with in-hospital mortality rates typically $<10 \%$ with this strategy. ${ }^{13-15}$ Although interventional therapies may struggle to improve on medical management in the acute setting, when one examines longer term follow-up data, the results of medical management are less satisfactory. Data from IRAD reveal 3-year survival of medically managed patients discharged alive after hospitalization for acute type B dissection to be only $78 \% .{ }^{16}$ Admittedly, a significant proportion of the late mortality is the result of patient comorbid conditions, but numerous studies have demonstrated that $25 \%$ to $50 \%$ of medically treated patients develop late aortic-related complications, most commonly aneurysmal degeneration of the false lumen. ${ }^{1}$ The upper thoracic aorta appears to be the major site of aneurysmal degeneration, with patency of the false lumen being the major risk factor for a late increase in aortic size. ${ }^{17}$

Given that numerous reports have found that a thrombosed false lumen predicts lower event rates after type B dissection, ${ }^{18}$ many have speculated that prophylactic TEVAR for uncomplicated type B dissection may promote

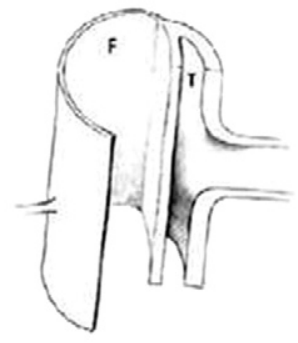

A

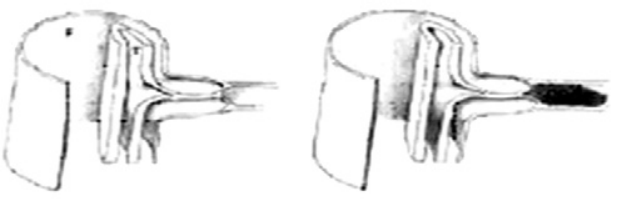

C

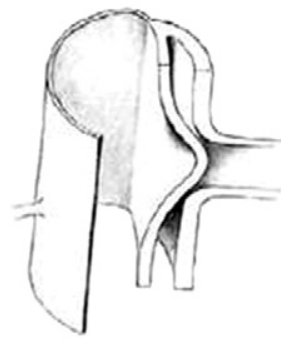

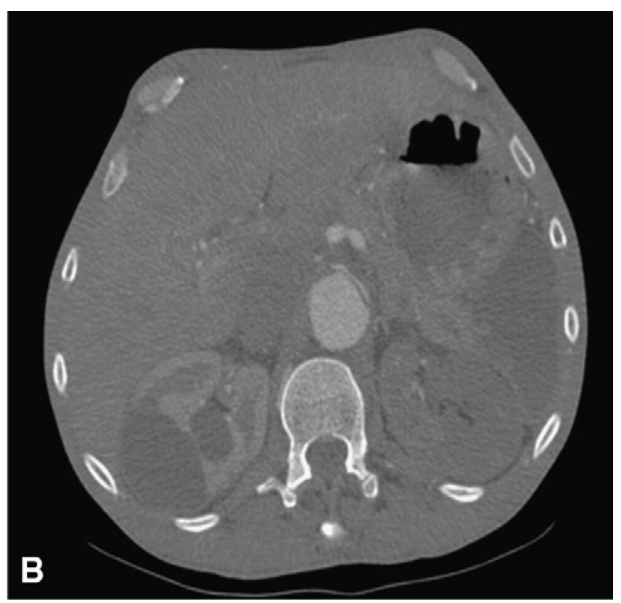

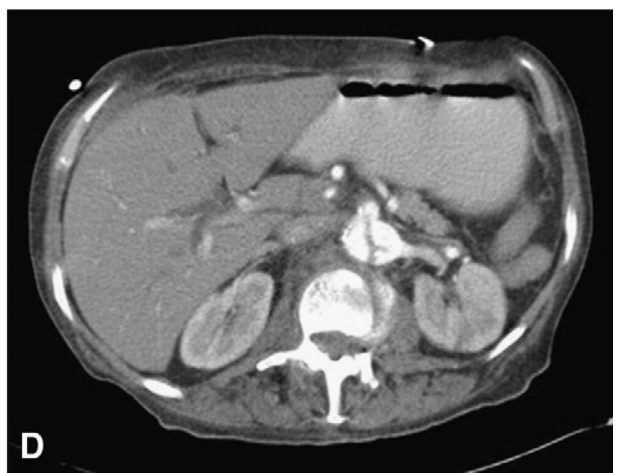

FIGURE 1. Malperfusion syndromes. A, Dynamic malperfusion results in branch vessel obstruction by the intimal flap. The degree of obstruction can vary with changes in the cardiac cycle as well as with variations in pressure in the false lumen. This type of malperfusion syndrome is generally relieved via restoration of antegrade true lumen flow. B, Computed tomographic angiogram demonstrating dynamic malperfusion of the celiac axis. C, Static malperfusion results from extension of the dissection process into the branch vessel with subsequent distal occlusion. This malperfusion syndrome is not relieved by restoration of antegrade true lumen flow and requires branch vessel stenting or surgical bypass. D, Computed tomographic angiogram demonstrating static malperfusion of the superior mesenteric artery (SMA). Note that the dissection extends out into the SMA and that both true and false lumens are occluded distally within the SMA. ${ }^{2,3} F=$ False lumen; $T=$ true lumen. Reprinted with permission from Elsevier. 


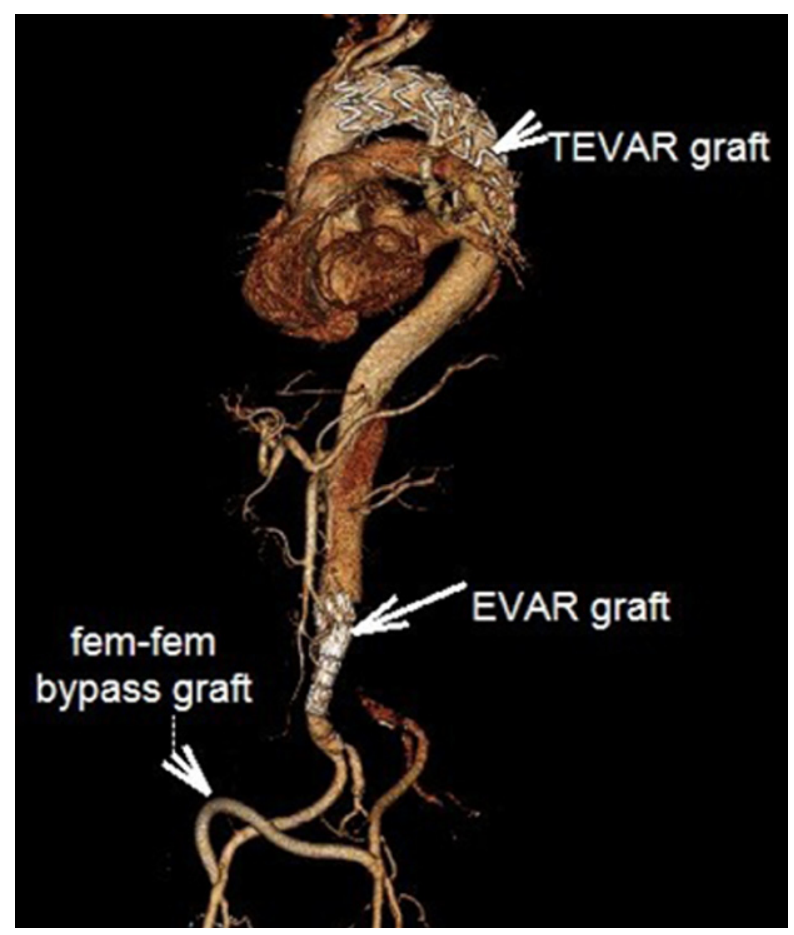

FIGURE 2. Computed tomographic angiography with 3-dimensional rendering demonstrating proximal thoracic endovascular aortic repair (TEVAR) with distal aorto-uni-iliac device placement and femoral-femoral (fem-fem) bypass for a patient with complicated acute type B dissection with long-segment unilateral iliac occlusion. EVAR, Endovascular aortic repair.

false lumen thrombosis and prevent late aneurysm formation. The Investigation of Stent Grafts in Aortic Dissection trial attempted to study this question. The trial randomized low-risk, subacute (2-52 weeks from symptom onset) type B dissection patients to TEVAR or optimal medical management and found no difference in the primary end point of all-cause mortality at 2 years. ${ }^{19}$ Patients randomized to TEVAR did have significantly greater aortic remodeling, defined as true lumen recovery with thoracic false lumen thrombosis, which occurred in $91.3 \%$ of TEVAR patients versus only $19.4 \%$ of medically managed patients $(P<.001)$. However, this did not translate into improved aorta-related survival, mainly because of a high rate of aorta-related deaths in the TEVAR group resulting from periprocedural technical complications. These complications, which included access vessel rupture, retrograde type A dissection, and thoracic aortic rupture despite TEVAR, were likely related to the short length of aortic pavement $(<15 \mathrm{~cm}$ in most patients) and the use of an earlier generation thoracic device suboptimal for this application. The complication rate observed was much higher than would be considered acceptable in more recent series using devices better suited to this application. ${ }^{20}$ Furthermore, the trial had other limitations and does not

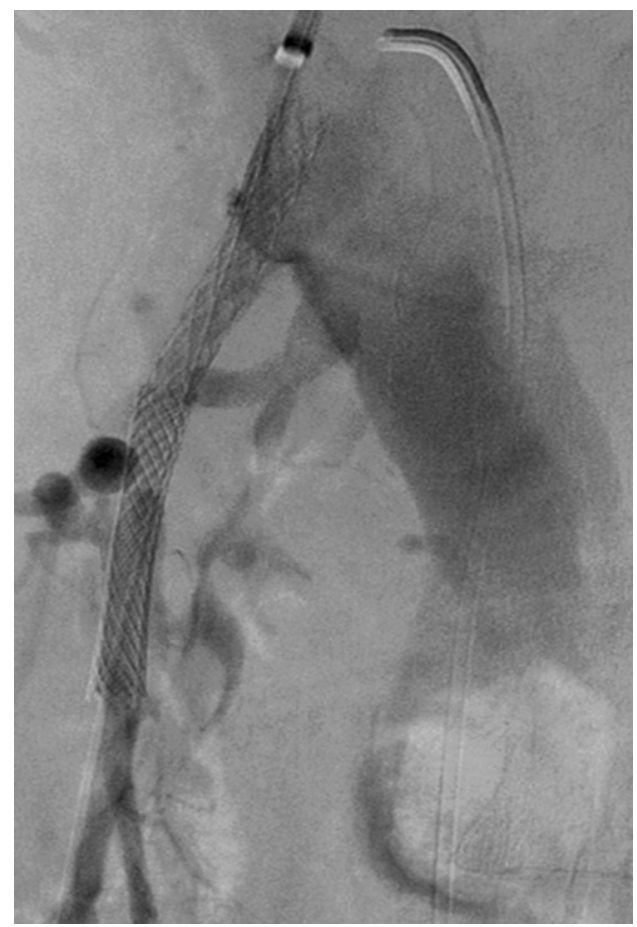

FIGURE 3. Subtraction angiography demonstrating bare-metal stenting of the superior mesenteric artery (SMA) with restoration of distal flow in a patient (computed tomographic scan shown in Figure 1, D) with acute complicated type B dissection with static SMA malperfusion.

represent the final word on this subject. Most notably, only patients who survived 2 weeks after symptom onset without intervention were included in the trial, potentially excluding high-risk patients who would be expected to derive the greatest benefit from early intervention. Last, although the results of medical management were good

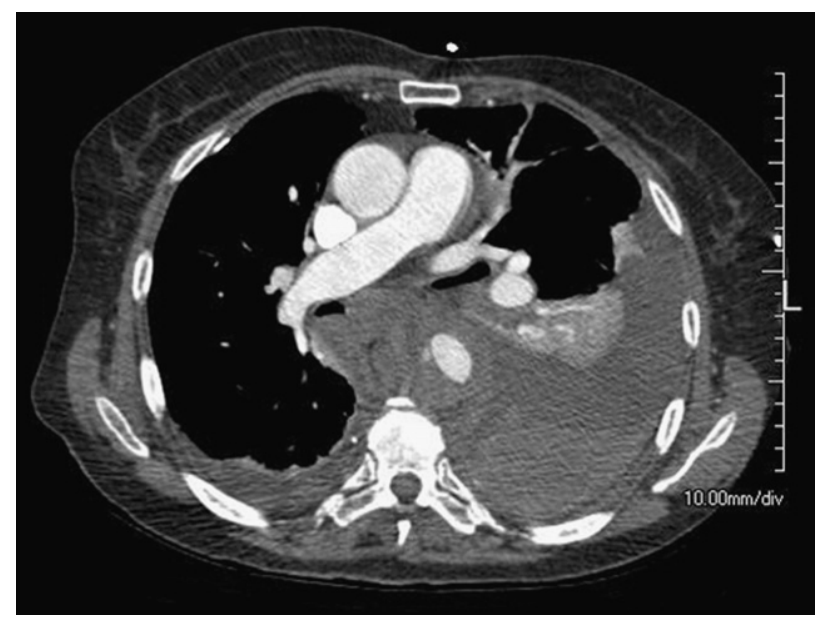

FIGURE 4. Acute type B dissection complicated by contained rupture into the left hemithorax. 


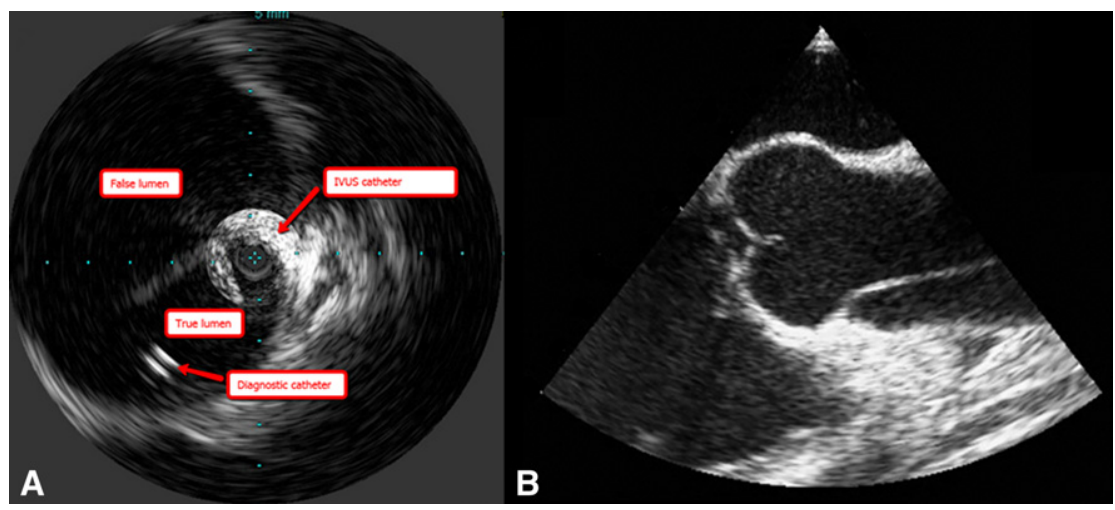

FIGURE 5. A, Intravascular ultrasound (IVUS) demonstrating true and false lumens and confirming true lumen guidewire access. B, Transesophageal echocardiography assessment of the proximal aorta at case completion demonstrating new retrograde type A dissection.

for these low-risk patients, two thirds of the deaths in the medical management group were secondary to aortic rupture.

A number of studies have suggested several subsets of high risk uncomplicated patients who may benefit from early TEVAR. Specific predictors of early or late adverse events identified in multiple studies include an initial aortic diameter $\geq 4.0 \mathrm{~cm}$ with a patent false lumen, ${ }^{15,21,22}$ an initial false lumen diameter $\geq 22 \mathrm{~mm}$ in the proximal descending aorta, ${ }^{23}$ recurrent/refractory pain or hypertension, ${ }^{24}$ or intramural hematoma with development of a penetrating atherosclerotic ulcer in the proximal descending aorta ${ }^{15,22}$ (Table 1$)$. However, uncertainty remains regarding the optimal management strategy for high-risk uncomplicated acute type B dissection, and the final answer to this question awaits a well-designed, prospective, randomized controlled trial.

\section{LONG-TERM MANAGEMENT}

Long-term mortality after hospital discharge is greater for type B dissection than for type A dissection, and attentive medical management and aortic surveillance are required. Specific predictors of follow-up mortality include female gender, prior aortic aneurysm, atherosclerosis, pleural effusion, and in-hospital acute renal failure, hypotension, or shock. ${ }^{16}$ Medical management with

TABLE 1. High-risk features of uncomplicated type B dissection

\begin{tabular}{lc}
\hline \multicolumn{1}{c}{ Clinical feature } & References \\
\hline Initial aortic diameter $\geq 4.0 \mathrm{~cm}$ with patent false lumen & $15,21,22$ \\
Initial false lumen diameter $\geq 22 \mathrm{~mm}$ in proximal DTA & 23 \\
IMH with PAU in proximal DTA & 15,22 \\
Recurrent/refractory pain or hypertension & 24 \\
\hline
\end{tabular}

$D T A$, Descending thoracic aorta; $I M H$, intramural hematoma; $P A U$, penetrating atherosclerotic ulcer. $\beta$-blockade and blood pressure control remains the cornerstone of long-term therapy for type $\mathrm{B}$ dissection ${ }^{25}$; however, a recent report from IRAD also found that the use of calcium channel blockers at discharge was associated with improved long-term survival selectively in medically treated type B dissection patients. ${ }^{26}$ The mechanism of this mortality benefit was unclear, and the authors speculated that the findings may be the result of differences in the typically more elderly type B patient population as well as potential selective effects of calcium channel blockers on descending aortic remodeling. Regardless, the authors consider the results preliminary and hypothesis generating, and stress the need for randomized controlled trials to define more completely optimal medical management in this population. ${ }^{26}$

Despite optimal medical management, at least one third of patients will require surgery for aortic-related complications within 5 years of the initial dissection, and the risk is most substantial within the first few months. Serial imaging at 1, 3, 6, and 12 months after discharge, and annually thereafter, is therefore recommended to allow for timely recognition and surgical repair of late problems of type B dissection, most commonly aneurysmal degeneration of a patent false lumen. ${ }^{25}$

\section{CONCLUSIONS}

Treatment options for type B aortic dissection are evolving in the endovascular era. Medical management remains the preferred strategy for uncomplicated acute type B dissection, and medical compliance is critical (Figure 6). There remains little or no debate in the literature regarding the preferred choice of TEVAR for acute complicated type B dissection, but the potential role for TEVAR for high-risk uncomplicated type B dissection requires additional study. Close lifelong aortic surveillance to identify and repair problems of chronic dissection is mandatory for all patients. 


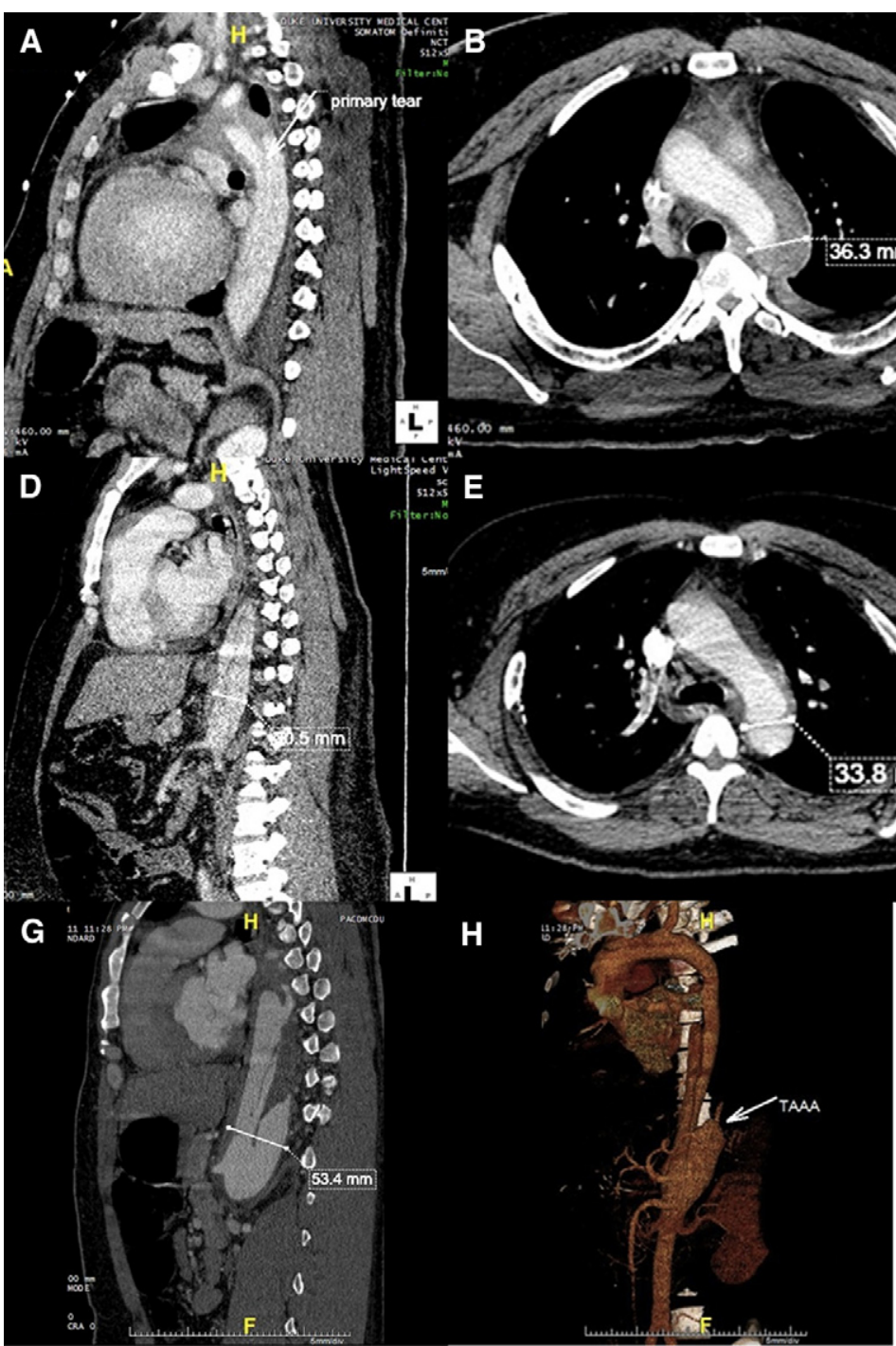

FIGURE 6. A case of type B dissection with rapid aneurysmal dilation resulting from medical noncompliance. A-C, A 30-year-old male with a history of malignant hypertension presented with an uncomplicated acute type B dissection with no high-risk anatomic features and was treated by medical management. D-F, At the 1-month follow-up visit, aortic diameters were stable but the patient's blood pressure was poorly controlled. G and H, The patient missed all subsequent follow-up appointments and re-presented 16 months later with hypertensive urgency resulting from medical noncompliance. The maximal aortic diameter was found to have enlarged by $2 \mathrm{~cm}$ over the 16-month interval and was treated successfully by open extent 1 thoracoabdominal aortic aneurysm $(T A A A)$ repair.

\section{References}

1. Coady MA, Ikonomidis JS, Cheung AT, Matsumoto AH, Dake MD, Chaikof EL, et al. Surgical management of descending thoracic aortic disease: open and endovascular approaches: a scientific statement from the American Heart Association. Circulation. 2010;121:2780-804.

2. Atkins MD Jr, Black JH III, Cambria RP. Aortic dissection: perspectives in the era of stent-graft repair. J Vasc Surg. 2006;43:30A-43A.

3. Parsa CJ, Hughes GC. Surgical options to contend with thoracic aortic pathology. Semin Roentgenol. 2009;44:29-51.

4. Parsa CJ, McCann RL, Hughes GC. Novel approach to the treatment of distal malperfusion secondary to ascending aortic dissection. J Card Surg. 2010;25: 220-2.

5. Koschyk DH, Nienaber CA, Knap M, Hofmann T, Kodolitsch YV, Skriabina V, et al. How to guide stent-graft implantation in type B aortic dissection? Comparison of angiography, transesophageal echocardiography, and intravascular ultrasound. Circulation. 2005;112:I260-4.
6. Eggebrecht H, Thompson M, Rousseau H, Czerny M, Lonn L, Mehta RH, et al. Retrograde ascending aortic dissection during or after thoracic aortic stent graft placement: insight from the European Registry on Endovascular Aortic Repair Complications. Circulation. 2009;120:S276-81.

7. Williams JB, Andersen ND, Bhattacharya SD, Scheer E, Piccini JP, McCann RL, et al. Retrograde ascending aortic dissection as an early complication of thoracic endovascular aortic repair. $J$ Vasc Surg. 2012 Jan 20 [Epub ahead of print].

8. Cooper DG, Walsh SR, Sadat U, Hayes PD, Boyle JR. Treating the thoracic aorta in Marfan syndrome: surgery or TEVAR? J Endovasc Ther. 2009;16:60-70.

9. Waterman AL, Feezor RJ, Lee WA, Hess PJ, Beaver TM, Martin TD, et al. Endovascular treatment of acute and chronic aortic pathology in patients with Marfan syndrome. J Vasc Surg. 2012 Mar 31 [Epub ahead of print].

10. Fattori R, Tsai TT, Myrmel T, Evangelista A, Cooper JV, Trimarchi S, et al. Complicated acute type B dissection: is surgery still the best option? A report from the International Registry of Acute Aortic Dissection. JACC Cardiovasc Interv. 2008;1:395-402. 
11. Parker JD, Golledge J. Outcome of endovascular treatment of acute type B aortic dissection. Ann Thorac Surg. 2008;86:1707-12.

12. Svensson LG, Kouchoukos NT, Miller DC, Bavaria JE, Coselli JS, Curi MA, et al. Expert consensus document on the treatment of descending thoracic aortic disease using endovascular stent-grafts. Ann Thorac Surg. 2008;85: S1-41.

13. Glower DD, Fann JI, Speier RH, Morrison L, White WD, Smith LR, et al. Comparison of medical and surgical therapy for uncomplicated descending aortic dissection. Circulation. 1990;82:IV39-46.

14. Hagan PG, Nienaber CA, Isselbacher EM, Bruckman D, Karavite DJ, Russman PL, et al. The International Registry of Acute Aortic Dissection (IRAD): new insights into an old disease. JAMA. 2000;283:897-903.

15. Winnerkvist A, Lockowandt U, Rasmussen E, Radegran K. A prospective study of medically treated acute type B aortic dissection. Eur J Vasc Endovasc Surg. 2006;32:349-55.

16. Tsai TT, Fattori R, Trimarchi S, Isselbacher E, Myrmel T, Evangelista A, et al. Long-term survival in patients presenting with type B acute aortic dissection: insights from the International Registry of Acute Aortic Dissection. Circulation. 2006; 114:2226-31.

17. Sueyoshi E, Sakamoto I, Hayashi K, Yamaguchi T, Imada T. Growth rate of aortic diameter in patients with type B aortic dissection during the chronic phase. Circulation. 2004;110:II256-61.

18. Erbel R, Oelert H, Meyer J, Puth M, Mohr-Katoly S, Hausmann D, et al. Effect of medical and surgical therapy on aortic dissection evaluated by transesophageal echocardiography: implications for prognosis and therapy: the European Cooperative Study Group on Echocardiography. Circulation. 1993; 87:1604-15.
19. Nienaber CA, Rousseau H, Eggebrecht H, Kische S, Fattori R, Rehders TC, et al Randomized comparison of strategies for type B aortic dissection: the INvestigation of STEnt Grafts in Aortic Dissection (INSTEAD) trial. Circulation. 2009; 120:2519-28.

20. Parsa CJ, Schroder JN, Daneshmand MA, McCann RL, Hughes GC. Midterm results for endovascular repair of complicated acute and chronic type B aortic dissection. Ann Thorac Surg. 2010;89:97-102; discussion 102-4.

21. Marui A, Mochizuki T, Koyama T, Mitsui N. Degree of fusiform dilatation of the proximal descending aorta in type $\mathrm{B}$ acute aortic dissection can predict late aortic events. J Thorac Cardiovasc Surg. 2007;134:1163-70.

22. Kitai T, Kaji S, Yamamuro A, Tani T, Kinoshita M, Ehara N, et al. Impact of new development of ulcer-like projection on clinical outcomes in patients with type B aortic dissection with closed and thrombosed false lumen. Circulation. 2010;122: S74-80.

23. Song JM, Kim SD, Kim JH, Kim MJ, Kang DH, Seo JB, et al. Long-term predictors of descending aorta aneurysmal change in patients with aortic dissection. $J$ Am Coll Cardiol. 2007;50:799-804.

24. Trimarchi S, Eagle KA, Nienaber CA, Pyeritz RE, Jonker FH, Suzuki T, et al. Importance of refractory pain and hypertension in acute type B aortic dissection: insights from the International Registry of Acute Aortic Dissection (IRAD). Circulation. 2010;122:1283-9.

25. Erbel R, Alfonso F, Boileau C, Dirsch O, Eber B, Haverich A, et al. Diagnosis and management of aortic dissection. Eur Heart J. 2001;22:1642-81.

26. Suzuki T, Isselbacher EM, Nienaber CA, Pyeritz RE, Eagle KA, Tsai TT, et al Type-selective benefits of medications in treatment of acute aortic dissection (from the International Registry of Acute Aortic Dissection [IRAD]). Am J Cardiol. 2012;109:122-7. 